\title{
GENDER DIFFERENCE ON CASE DETECTION OF PULMONARY TUBERCULOSIS AMONG THE SUSPECTED CASES ATTENDING IN JUTPANI PRIMARY HEALTH CENTRE OF CHITWAN, NEPAL
}

\author{
Amgain $\mathrm{K}^{1}$, Paudel DP², Paneru DP³ ${ }^{3}$ Dhital $\mathrm{M}^{4}$, Amgain $\mathrm{G}^{5}$ \\ ${ }^{1}$ Tribhuvan University, Central Department of Zoology, University Campus, Kirtipur, Kathmandu, Nepal \\ 2 Department of Public Health, JN Medical College, KLE University, Nehru Nagar, Belgaum, Karnataka, India \\ ${ }^{3}$ Department of Public Health, Pokhara University, Kaski, Nepal \\ ${ }^{4}$ JN Medical College, KLE University, Nehru Nagar, Belgaum, Karnataka, India \\ ${ }^{5}$ Tribhuvan University, Central Department of Phychology, University Campus, Kirtipur, Kathmandu, Nepal
}

\begin{abstract}
Introduction: Pulmonary tuberculosis is one of the World's public health problems particularly in developing countries including Nepal. Every year, thousands of people suffered from active tuberculosis in Nepal; of whom 50 percent have infectious pulmonary tuberculosis. It is more common among men than women, and affects mostly adults of economically productive age. There is scantiness of such information in Nepal. Hence the study was carried out to identify the gender difference on case identification of pulmonary tuberculosis in Chitwan district of Nepal.
\end{abstract}

Methodology: Descriptive cross sectional study was carried out from July to December 2012 in Jutpani Village Development Committee of Chitwan, Nepal. All symptomatic cases attending in Jutpani Primary Health Center with the clinical history pulmonary tuberculosis were included. Microscopic examination of sputum samples of three consecutive days was done for AFB. Results were disseminated in tabular, graphical and narrative form using appropriate statistics.

Results: Total 200 suspected cases of pulmonary tuberculosis were included in this study; among them $18(9 \%)$ were found to be AFB positive. Sex ratio of diagnosed patients was $5: 4$ (male; $55.56 \%$ and female; $44.44 \%)$. Highest prevalence of TB infection (36.89\%) was found in 30-40 years age. Highest number of cases $5(27.78 \%)$ were reported in the ward number four (male female ratio; $3: 2)$. One-third of cases were in July followed by $22.22 \%$ in each of the month; August and September.

Conclusion: Males were found to be more likely to have pulmonary tuberculosis than females. Gender specific case identification and preventive measure targeting to the most productive age group population will eventually supports to reduce the risk of pulmonary tuberculosis.

Key words: Pulmonary Tuberculosis, Case Detection, Gender Difference, Suspected Cases

\section{INTRODUCTION}

Pulmonary tuberculosis (PTB) is one of the World's public health threat particularly in developing countries including Nepal. ${ }^{1}$ It is the second leading cause of death due to infectious disease

Correspondence:

Dillee Prasad Paudel

M.Ed. MPH, Ph.D. Scholar

Department of Public Health

JN Medical College, KLE University

Nehru Nagar, Belgaum, Kartnataka, India

E-mail: Paudeldp@gmail.com
Worldwide. ${ }^{1-2}$ Globally; almost nine million new PTB cases had been detected and 1.4 million people died due to the same in 2011..$^{3-4}$ India and China; the neighboring countries of Nepal, covered almost 40 percent of the world's tuberculosis cases ${ }^{4}$ Nepal is also vulnerable to such problems and thousands of people suffered from active tuberculosis every year; of which 50 percent have infectious pulmonary tuberculosis. ${ }^{5}$ Some gender differentiate have been reported in PTB from different parts of the world; majority are male of productive age group. Nearly twice as many men died from tuberculosis with compare to women. Even so, more women died of TB than from all other 
maternal conditions. ${ }^{6}$ Gender inequality has long been identified as a major determinant that can lead to delay in diagnosis, poor access to health care, lack of compliance and also poor treatment outcomes. Health care seeking and treatment behavior of men and women suffering from tuberculosis (TB) is largely determined by how they and those around them perceive the symptoms, regard the diagnosis, accept the treatment, and adhere with it. ${ }^{7}$ World Health Organization (WHO) has encouraged gender specific comparisons in TB rates to determine whether women with TB are less likely than men with TB to be diagnosed, reported, and treated. ${ }^{8}$ Moreover there is scantiness of such information in Nepal. Hence the study has been carried out to identify the gender difference of pulmonary tuberculosis and its distribution pattern and burden in the rural community of central Nepal.

\section{METHODOLOGY}

A descriptive cross sectional study was carried out in Jutpani Primary Health care Centre (PHC) of Chitwan district, Nepal during July to December 2012. The PHC covers six Village Development Committees (VDC) including Jutpani VDC. Furthermore the VDC has been divided in nine wards as the peripheral level administrative unit by the government of Nepal. All together 200 TB suspected patients from Jutpani VDC visited to PHC during the period of July to December 2012 with the clinical history of two or more week's continuous cough, fever, and marked weight loss were included as the study population. All the potential participants (suspected cases) were briefed about aim of study and oriented for proper collection of the sputum sample. Sputum samples of three consecutive days from all suspected patients were examined microscopically using Z-N staining for Acid Fast Bacilli (AFB) at the PHC.

Due to the inconvenient of sputum sample collection, patients $<10$ years of age were excluded from this study. Verbal informed consent was taken before the collection and testing of sample. Ethical clearance was taken from the Institutional Research Board of Central Department of zoology, Tribhuvan University of Nepal. This study was carried out to measure the distribution pattern of pulmonary tuberculosis according to the sex, place and time. Detection of other forms of TB was technically and operationally not feasible in the
DOTS centre. Hence only pulmonary tuberculosis was considered for this study. Brief demographic and clinical history was taken by using the pre designed format (proforma) before collection of sputum sample.

Data accuracy and reliability was maintained by double entry into the SPSS version 20. Percentage, mean, standard deviation and proportion were calculated as univarate analysis and chi-square (X2) tests, sensitivity, specificity, and predictive (positive and negative) values were calculated as bivarate analysis. The criterion for statistical significance was set at the value of $p<0.05$. The analyzed data were disseminated in tables, graphs/ charts and narrative form as per necessity.

\section{RESULTS}

All together 200 TB suspected patients (having the age; Mean \pm SD: $38.1 \pm 9.71$ years) were participated in this study. Of which; $18(9 \%)$ were found smear positive and diagnosed as PTB by smear microscopy. Out of total smear positive cases, $10(55.56 \%)$ were male and $8(44.44 \%)$ were female (Table 1). The highest prevalence of sputum positivity $(38.89 \%)$ was found in the age group of 30-39 years (male positive; $16.67 \%$ < female positive; $22.22 \%$ ) followed by $22.22 \%$ in the age group 20-29 years (male positive; $5.56 \%$ $<$ female positive; $16.67 \%$ ). Two age groups (1020 years and $50-59$ years) were found to have the same rate of positivity $(11.11 \%$ in each ) of total TB positive in grant while there was sex wise differentiation ( male $11.11 \%$ and female $0 \%$ ) in the age group 10-20 years and equal (male : female $=1: 1$ ) in the other age group 50-59. The least number of positive cases $(5.55 \%)$ were found in the other age groups; $40-49$ and $>70$ years respectively (Table 2 ).

Table 1. Gender based positive cases of pulmonary tuberculosis

\begin{tabular}{|c|c|c|}
\hline \multirow{2}{*}{ Sex } & \multicolumn{2}{|c|}{ Cases (suspected and smear positive) } \\
\cline { 2 - 3 } & Suspected cases & AFB Positive cases \\
\hline Male & $96(48.00)$ & $10(55.56)$ \\
\hline Female & $104(52.00)$ & $8(44.44)$ \\
\hline Total & $200(100.00)$ & $18(100.00)$ \\
\hline
\end{tabular}

(Note: figures inside the bracket indicate the percentage value) 


\begin{tabular}{|c|c|c|c|c|c|c|}
\hline \multirow{2}{*}{$\begin{array}{l}\text { Age in } \\
\text { years }\end{array}$} & \multicolumn{2}{|c|}{ Male Patients } & \multicolumn{2}{|c|}{ Female patients } & \multirow{2}{*}{$\begin{array}{c}\text { Total suspected } \\
\text { cases }\end{array}$} & \multirow{2}{*}{$\begin{array}{c}\text { Total positive } \\
\text { cases }\end{array}$} \\
\hline & $\begin{array}{l}\text { Suspected } \\
\text { cases }\end{array}$ & $\begin{array}{l}\text { Positive } \\
\text { cases }\end{array}$ & $\begin{array}{c}\text { Suspected } \\
\text { cases }\end{array}$ & $\begin{array}{l}\text { Positive } \\
\text { cases }\end{array}$ & & \\
\hline 10- 19 & $21(10.50)$ & $2(11.11)$ & $19(9.50)$ & $0(0.00)$ & $40(20.00)$ & $2(11.11)$ \\
\hline $20-29$ & $13(6.50)$ & $1(5.56)$ & $27(13.50)$ & $3(16.67)$ & $40(20.00)$ & $4(22.22)$ \\
\hline $30-39$ & $13(6.50)$ & $3(16.67)$ & $23(11.50)$ & $4(22.22)$ & $36(18.00)$ & $7(38.89)$ \\
\hline $40-49$ & $12(6.00)$ & $1(5.56)$ & $13(6.50)$ & $0(0.00)$ & $25(12.50)$ & $1(5.56)$ \\
\hline $50-59$ & $20(10.00)$ & $1(5.56)$ & $14(7.00)$ & $1(5.56)$ & $34(17.00)$ & $2(11.11)$ \\
\hline $60-69$ & $9(4.50)$ & $1(5.56)$ & $6(3.00)$ & $0(0.00)$ & $15(7.50)$ & $1(5.56)$ \\
\hline$\geq 70$ & $8(4.00)$ & $1(5.56)$ & $2(1.00)$ & $0(0.00)$ & $10(5.00)$ & $1(5.56)$ \\
\hline Total & $96(48.00)$ & $10(55.56)$ & $104(52.00)$ & $8(44.44)$ & $200(100.00)$ & $18(100)$ \\
\hline
\end{tabular}

(Note: Figures inside the brackets indicate the percentage value)

Table 3. Ward wise case detection of PTB on the basis of gender difference

\begin{tabular}{|c|c|c|c|c|c|c|}
\hline \multirow[b]{2}{*}{ Ward No. } & \multicolumn{2}{|c|}{ Male patients } & \multicolumn{2}{|c|}{ Female patients } & \multirow{2}{*}{$\begin{array}{c}\text { Total } \\
\text { suspected } \\
\text { cases (N \%) }\end{array}$} & \multirow[b]{2}{*}{$\begin{array}{l}\text { Total positive } \\
\text { cases (N \%) }\end{array}$} \\
\hline & $\begin{array}{c}\text { Suspected } \\
\text { cases (N \%) }\end{array}$ & $\begin{array}{c}\text { Positive cases } \\
(\mathrm{N} \%)\end{array}$ & $\begin{array}{c}\text { Suspected } \\
\text { cases (N \%) }\end{array}$ & $\begin{array}{c}\text { Positive cases } \\
(\mathrm{N} \%)\end{array}$ & & \\
\hline One & $17(8.50)$ & $2(11.11)$ & $24(12.00)$ & $2(11.11)$ & $41(20.50)$ & $4(22.22)$ \\
\hline Two & $6(3.00)$ & $0(0.00)$ & $6(3.00)$ & $0(0.00)$ & $12(6.00)$ & $0(0.00)$ \\
\hline Three & $8(4.00)$ & $1(5.56)$ & $4(2.00)$ & $0(0.00)$ & $12(6.00)$ & $1(5.56)$ \\
\hline Four & $28(14.00)$ & $3(16.67)$ & $34(17.00)$ & $2(11.11)$ & $62(31.00)$ & $5(27.78)$ \\
\hline Five & $4(2.00)$ & $1(5.56)$ & $7(3.50)$ & $1(5.56)$ & $11(5.50)$ & $2(11.11)$ \\
\hline Six & $1(0.50)$ & $0(0.00)$ & $4(2.00)$ & $1(5.56)$ & $5(2.50)$ & $1(5.56$ \\
\hline Seven & $2(1.00)$ & $0(0.00)$ & $4(2.00)$ & $1(5.56)$ & $6(3.00)$ & $1(5.56)$ \\
\hline Eight & $19(9.50)$ & $2(11.11)$ & $14(7.00)$ & $1(5.56)$ & $33(16.50)$ & $3(16.67)$ \\
\hline Nine & $11(5.50)$ & $1(5.56)$ & $7(3.50)$ & $0(0.00)$ & $18(9.00)$ & $1(5.56)$ \\
\hline Total & $96(48.00)$ & $10(55.56)$ & $104(52.00)$ & $8(44.44)$ & $200(100.00)$ & $18(100.00)$ \\
\hline
\end{tabular}

(Note: Figures inside the brackets indicate the percentage value)

In this study the study area has been divided in nine administrative units called wards. Among total 200 suspected cases, $62(31 \%)$ were found in ward number four followed by $21.5 \%, 16.5 \%$ and $9 \%$ in ward number one, eight and nine respectively. Fewer cases were suspected in ward umber two $(6 \%)$, three $(6 \%)$, five $(5.5 \%)$, seven (3\%) and six $(2.5 \%)$. Similarly out of total 18 smear positive cases, highest prevalence of tuberculosis was found in the ward number four (27.77\%) followed by the ward number one $(22.22 \%)$, eight $(16.66 \%)$ and five $(11.11 \%)$. Only one case $(5.55 \%)$ was diagnosed as smear positive in each of remaining wards (ward number three, six, seven and nine). The male female ratio of pulmonary positive cases in each of wards from one to nine was 1:1, 0:0,1:0, 3:2, 1:1, 0:1, 0:1, 2:1and 1:0 respectively (Table 3).

The study revealed (as shown in figure 1) that the highest suspected cases were found in the month of September in both sexes (female (19.5\%) > male $(11 \%))$. More or less similar number of cases found in October (male:11\%; female 11.5\%), November (male:5\%; female: $4.5 \%$ ) and December (male: 8; female:7.5\%) where as a lowest number of cases with some of variation in male and female (male $(5.5 \%)>$ female $(3.5 \%)$ ) found in the month of August. Amongst total smear positive cases, the highest number of positive male cases (22.22\%) 
found in the month of July measured as double as female positive case (11.11\%) in the same month. Similarly the highest female positive cases $(16.67 \%)$ were detected in the month of October which is three folds more than male positive cases $(5.55 \%)$ in the same month. Similarly $11.11 \%$ of male positive cases were detected in the month of September but no female positive cases were detected in the same time. In the month of August, October, November and December only one $(5.55 \%)$ positive male case was detected in each month where as $2(11.11 \%)$ and $3(16.66 \%)$ of positive female cases were detected in the same months; August and October with no female positive cases in November and December (Figure 1).

The study revealed that, there was more than $10 \%$ variation in suspected cases of male and female however there was no significant difference $\left(X^{2}=0.452\right.$ at $\left.d f=1, p>0.05\right)$ in gender difference of positivity of pulmonary tuberculosis. The true positive case detection rate (sensitivity) was only $55.55 \%$ while the true negative case detection rate (specificity) was $52.74 \%$. Similarly the positive predictive value of pulmonary tuberculosis was only $10.4 \%$ meanwhile the negative predictive value was $92.3 \%$ as shown in table 4 .

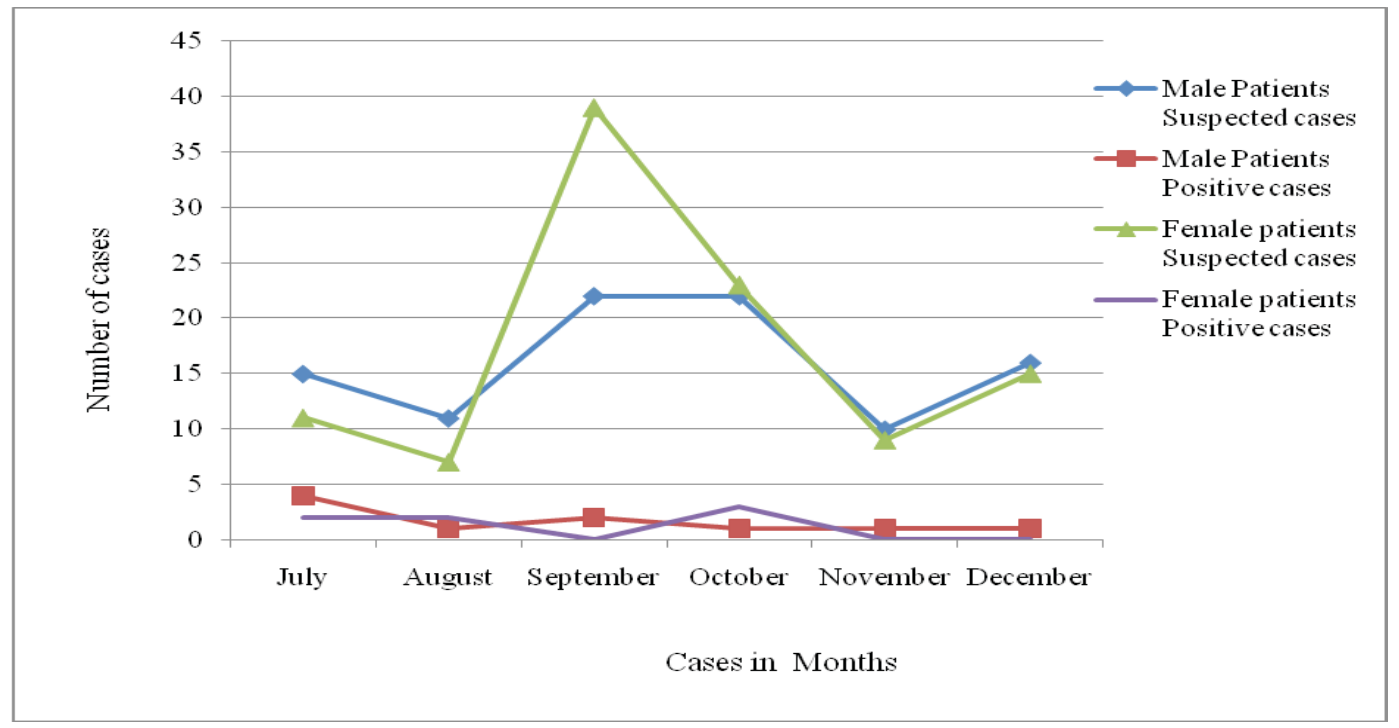

Figure 1. Month wise suspected cases and AFB positive male and female cases

\begin{tabular}{|c|c|c|c|c|}
\hline \multirow{2}{*}{ Sex } & \multicolumn{3}{|c|}{$\begin{array}{c}\text { PTB among suspected } \\
\text { cases }\end{array}$} & \multirow{2}{*}{ Test value } \\
\hline & $\begin{array}{c}\text { AFB } \\
\text { Positive }\end{array}$ & $\begin{array}{c}\text { AFB } \\
\text { Negative }\end{array}$ & Total & \\
\hline Male & 10 & 86 & 96 & \multirow{3}{*}{$\begin{array}{l}X^{2}=0.452 \text { at } \\
d f=1 \\
p>0.05 \\
P P V=10.4 \%\end{array}$} \\
\hline Female & 8 & 96 & 104 & \\
\hline Total & 18 & 182 & 200 & \\
\hline
\end{tabular}

Note: $D f=$ degree of freedom, $P P V=$ Positive predictive value

\section{DISCUSSION}

The study revealed that one; out of every ten suspected cases were AFB positive. Among all smear positive cases, the male-female ratio was $5: 4$ which is in line with other similar study in Nepal and Pakistan ${ }^{9-12}$ but somehow differ with a study conducted in Tribhuvan University teaching Hospital Kathmandu that showed male female ratio of PTB as $47: 53 .{ }^{13}$ Similarly our study is contrasts with a study in Afghanistan which showed 31.5\% pulmonary tuberculosis occurred in males which was significantly lesser than female cases (68.5). ${ }^{14}$ Age wise observation of the smear positivity in this study revealed that the higher numbers of positive cases were found in the age group 20 to 39 years. There is no significant difference in sex wise positivity rate in this age group. This finding is supported by other study reports from Afghanistan, Hong Kong and Nepal. ${ }^{14-17}$ Study from Afghanistan showed the sex difference was greater in the 
middle age groups including $15-44$ years. ${ }^{12}$ Study by Chan-Yeung et al. from Hong Kong reported that the sex difference in TB was greater in older than in younger which is somehow consistent with our study findings. ${ }^{15-16}$ Study conducted, in Palpa and Kathmandu found the highest prevalence of TB among age group 20-30 years. ${ }^{16-17}$ Higher prevalence of TB in the age group 20-39 is because people of these age groups are exposed to the outer environment as well as due to high work load and wide range of mobility.

Present study revealed that ward wise prevalence was highest $(27.78 \%)$ in ward number four followed by ward number two (22.22\%) and eight $(16.67 \%)$. The proportion of male positive case detection was also higher (16.67\%) compared to female positives (11.11\%) in the community of ward number four and equal proportion (11.11\%) in ward number one where the prevalence is in second highest on ranking. The wards where the high proportion of cases found are remote rural areas ( $>5 \mathrm{KM}$ far from $\mathrm{PHC}$ ) where the health education and health care facilities are inaccessible with compare to other wards ( $<5 \mathrm{Km}$ from health facility) where the case detection proportion is low.

This study revealed that the prevalence of TB was found highest (one-third of total case detection) in July followed by August and September (22.22\%). Among total 18 smear positive cases, the highest number of positive male cases (22.22\%) found in the month of July which is double of female positive case $(11.11 \%)$ in the same month. Similarly the highest female positive cases (16.67\%) were detected in the month of October which is triple fold more than male positive cases $(5.55 \%)$ in the same month. The reason of high prevalence of PTB in the month of August might be due to high incidence of cough and cold which may help in the transmission of PTB during coughing in the month due to seasonal change. Study carried out in other parts of Nepal showed the similar results. ${ }^{6-18}$ Study from Hong Kong also showed the seasonal variation have significant role for occurring the pulmonary tuberculosis. The trough occurred in either January or February, while the peak occurred between May and August. ${ }^{19}$ Similarly study conducted in four countries; Mongolia, Moldova, Zimbabwe and Uganda showed a similar trend of case identification. ${ }^{19}$ Excess proportion of cases among suspects in June and July, followed by a considerable decline to below average proportions from August through December in Mongolia. Lower than expected proportions were found in March in Moldova and Zimbabwe and in April in Uganda, while a higher than expected prevalence was recorded in September in Zimbabwe. ${ }^{20}$

\section{CONCLUSION}

Males were found more likely to have pulmonary tuberculosis than females. Productive age group people were more vulnerable to PTB. There was no significant seasonal variation in PTB case identification though the suspected cases were high in September and October. Gender specific case identification and preventive measure targeting to the most productive age group population will eventually supports to reduce the risk of pulmonary Tuberculosis.

\section{REFERENCES}

1. Grange, JM, Greenwood, D, Slack RC, Peuthere JF. Medical Microbiology 1998, $15^{\text {th }}$ ed. ELBS Churchill Livingstone, UK, $215 \mathrm{p}$.

2. World Health Organization. Tuberculosis Control in the South-East Asia Region, Geneva, Switzerland 2012.

3. Miller B, Schieffelbein C. Tuberculosis, Bulletin. WHO 1998;76:141-43.

4. WHO. Global Tuberculosis Report. World Health Organization, Geneva, Switzerland 2012.

5. Annual Report 2010/2011. Ministry of Health and Population, Department of Health Services, Kathmandu, Nepal.

6. World Health Organization. The World Health Report: shaping the future. Geneva 2003.

7. Bashour H, Mamaree F. Gender differences and tuberculosis in the Syrian Arab Republic: patients' attitudes, compliance and outcomes. Eastern Mediterranean Health Journal 2003;9:27-38.

8. Uplekar M, Rangan S, Ogden J. Gender and tuberculosis control: towards a strategy for research and action, WHO/TB/2000.280. Geneva: World Health Organization, 1999. 
9. Smith I. Prevalence of Tuberculosis in Gorkha district, Nepal. Journal of the Nepal Medical Association; TB special 1994;18:14-19.

10. Iqbal Tn, Raziq Md A, Hussain Z, Anjum N, Atiq S. Gender differences among suspected pulmonary tuberculosis patients. Ann. Pak. Inst. Med. Sci. 2011;7: 14-17.

11. Joshi R S. Prevalence of Pulmonary Tuberculosis in relation to socio-behavioral aspects in patients visiting in Patan Hospital (M.Sc. Thesis in parasitology). Central Department of Zoology, Tribhuvan University; 2004.

12. Sharma SK. A study on prevalence of Pulmonary Tuberculosis among the suspected cases visiting in Gorkha District Hospital, Nepal and TB awareness among them (M.Sc. Thesis in parasitologiy). Central Department of Zoology, Tribhuvan University; 2008.

13. Shrestha HG. Extra-pulmonary tuberculosis in Nepal. Journal of the Nepal Medical Association 1989:9:16-23.

14. Sabawoon $W$, Sato $H$. Sex Difference in Tuberculosis in Afghanistan: A National Cohort Study. Mycobacterial Diseases 2012;2:1-5.
15. Kong Chan-Yeung M, Noertjojo K, Chan S L, Tam C M Sex differences in tuberculosis in Hong Kong. Int J Tuberc Lung Dis 2002;6:11-18.

16. Dhungana JR. Tuberculosis and HIV co-infection in patients attending Tansen Hospital, Palpa. (M.Sc. Thesis of microbiology). Central Department of Microbiology, Tribhuvan University, Kathmandu, Nepal 2002.

17. Dhungana GP. Tuberculosis and HIV co-infection in Kathmandu Valley (M.Sc. Thesis of microbiology). Central Department of Microbiology, Tribhuvan University, Kathmandu, Nepal; 2004.

18. NTC. Knowledge, Attitude and Practices Study on Tuberculosis among community People, Report of Sindhupalchok District. National Tuberculosis Center, Kathmandu, Nepal; 2009.

19. Leung CC, Chan CK, Yew WW, Tang N, Thomas YK Chiu Chang $C$ et al. Seasonal pattern of tuberculosis in Hong Kong. International Journal of Epidemiology 2005;34:924-30.

20. Mabaera B, Nymadawa N, Katamba A, Dumitru L, Jens ML, Hans L. Rieder. Seasonal variation among tuberculosis suspects in four countries. International Health 2009;1:53-60. 